\title{
Management Information System for Education
}

\author{
Hassan Aldarbesti, J. P. Saxena
}

\begin{abstract}
Data, information and decision process are linked to each other. Data after processing is transformed into information and information is the base for decision making process. It is very important to have relevant information for correct, timely and effective decisions to be made. Management Information System (MIS) has assumed great importance in this context. The paper explains the concept of data, information and MIS. The importance of MIS, its rapid growth and latest trends in MIS are discussed in the paper. Education sector has a special place in the agenda of any government due to its importance for well-being of the citizens and the country as a whole. Education Management Information System (EMIS) plays an important role in developing appropriate plans, strategies and policies for improving the education system. Case studies of EMIS of Nigeria and Zambia have been discussed briefly to learn lessons from their experiences. Paper suggests the desirable EMIS for better management of information in education sector.

Keywords: Education Management Information System (EMIS), Information, Management Information System (MIS), Trends in MIS.
\end{abstract}

\section{Introduction}

Performance of an organization to achieve its goals and objectives largely depends upon the resources available to it both from inside the organization or from outside. Various resources are required to perform, which include manpower, materials, finance, facilities and information. Information is one of the most important resource of the organization that have an impact on all the other resources. Availability of resources makes all the difference to an organization to compete in the market and excel. The growth and future of any organization whether a manufacturing unit, trading organization, business organization, service provider, government department or an educational institute depends on its resources and more so on their effective utilization. It is not enough to only arrange resources but their timely acquisition, utilization and monitoring is absolutely essential for the success of the organization. The management functions like planning, organizing, executing, monitoring, control and evaluation can be performed with the information.

\section{Data, Information and Decision Process}

The distinction between data and information is not very clear to some of the people. Raw facts, figures, objects, etc. are data. Data when processed is converted into information. Decision making process is dependent of information. Every organization has plenty of data but they lack from relevant information required for making the decision. If a decision is required to set up a management institute in a particular city, it requires pertinent information such as number of students passing graduation every year, number of students seeking admission in different stream, the growth pattern of students in each discipline, the job demand from business or industry, number of other institutes offering similar courses, number of students seeking admissions outside the country for similar courses and the reasons for preference to these institutes. The information on such aspects help the authorities to design the course according to the demand and completion in the market place. The same is true with other activities like industrial production, governance in the government sector, sports, entertainment, social welfare and social security. Even in case political election in various countries all the political parties collect information about number seats in each state, constitutes, the age profile of population, the gender distribution, religion following, details about minority communities, education pattern of the voters, distribution of voters by caste, the local issues as well as national and international issues and many more. The past voting pattern and the information on the performance of the present government are important to adopt appropriate strategies to win the information. Global and multi-national companies having their manufacturing units in various parts of the world with large number products, with large number of employees of various nationalities operating in different market conditions deal with big data. Analysis of big data for generating relevant information is a challenge in itself. Conversion of data into information including the management of database is a scientific approach which can be carried out by trained and qualified manpower only. Having too much of data and information is also not good for good decision making. In fact excess of data and information makes the decision process more difficult. What is needed the correct and reliable information, in right quantity, at a right time, at the right place and at affordable cost. The cardinal issue is to increase the value of information for better decision making. 


\subsection{Types of Information}

Harsh, Connor \& Schwab [1] suggested a classification of information into four categories: Descriptive Information, Diagnostic Information, Predictive Information and Prescriptive Information (Fig.1).

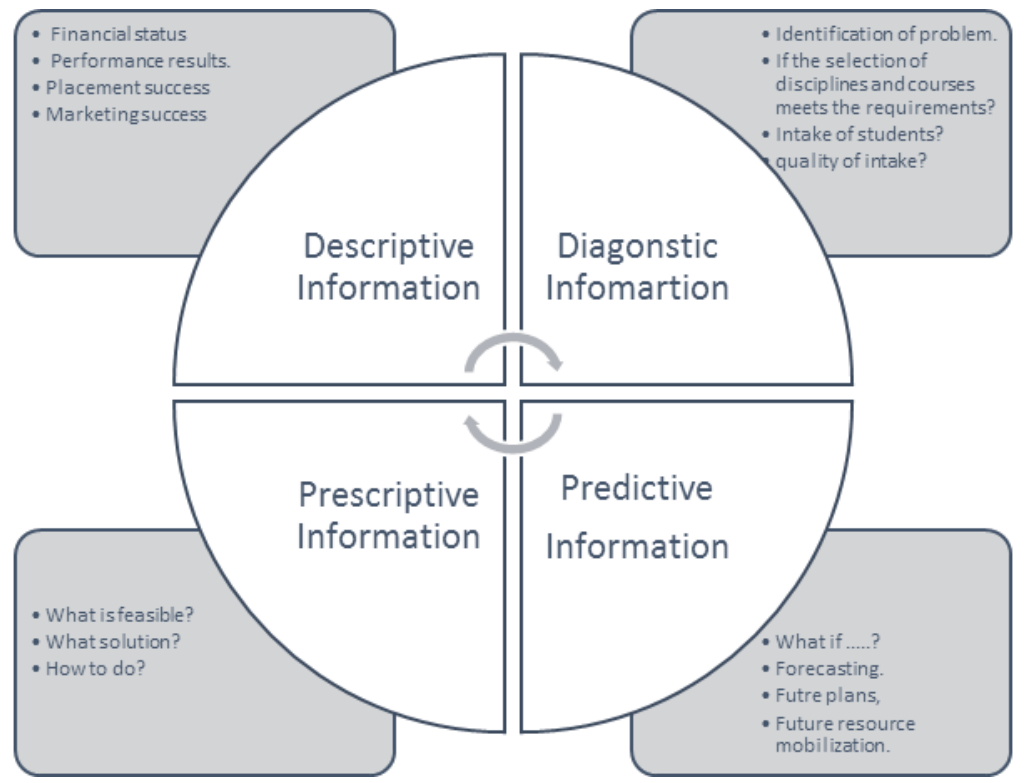

Fig. 1: Classification of information - Examples of Education System

\subsubsection{Descriptive information}

Staring point in the classification of information is the descriptive information, which is the base for all other types of information. Descriptive class of information scenario building of the business at a particular point of time. As an example of an education system, it deliberates about:

a. Number of students enrolled,

b. Disciplines and the courses running,

c. Placement process in vogue and its success,

d. Marketing strategy adopted and its impact on the enrollment, and

e. Recognition of its courses by the end users like industry, business houses, educational institutes and government etc.

\subsubsection{Diagnostic information}

Diagnostic information provides insight in to the problems. What are the reasons of the problems? What has not been done? What should have been done? These are the areas of coverage of diagnostic information. The types of information needed in this class of information in case of the education institutes are:

a. Why the registration of students is below expectation?

b. Where is more registration and why?

c. Which courses are more popular?

d. What are reasons of students taking admission in this institute?

e. Has the marketing strategy adopted given commensurate results?

f. Why students initially registered switched over to other institution?

g. Is the fees charged for the course competitive in comparison to other contemporary institutes? Based on the diagnostic information education planners and regulators set norms and standards. Gap analysis is carried out to identify the areas of concerns as well as areas of opportunities. The information available is used for appropriate action plans.

\subsubsection{Predictive information}

Predictive information is relating to question "What if...?" This class of information helps in analyzing the future strategies to be considered and adopted. This information attempts to identify the desirable outcomes. The predictive information is vital for forecasting, planning future strategies, looking for resource mobilization in coming years and what type of marketing strategies will be more practical. Budgeting techniques, simulation models and other management tools adopted by the organizations use predictive information extensively. 


\subsubsection{Prescriptive information}

Predictive information addresses the question of what should be done and what can be done. The basic source for such analysis is the domain of predictive information. The output of the predictive information is deliberated in the context of goals and values set for the organization. For example, an education institute may offer integrated courses which ensure the students for a steady education at a later date when they have to for higher education. The competition at that stage may be very critical. But a student of the same institute will have more chances to get admission in higher courses due to intimate knowledge of the standard and norms of the institute. Even the institute have more confidence on the likely performance of its own students. Some of the institutes offer dual degree where in part of the education is done in the mother institute and par of the education is imparted in an institute in another country. This institute can be the institute of the mother institute which has enrolled the student initially or in another institute totally independent identity but having a collaborative arrangement with the mother institutes. Students get a great advantage of world class exposer by studying in a foreign university which otherwise is beyond his means. The quality of education improves with such world class interactions. Students have an opportunity of interacting with world class faculty, study in a dream environment and compete on a world class syllabus as well as with world class student community.

\section{Management Information System (MIS)}

Correct decision making is possible with the efficient utilization of information. In view of the large data and information available to the managers, the decision making process becomes very difficult. Information required for decision making should be easily available [2]. Collection of data, its conversion to the information, proper storage of information, retrieval of information and effective utilization of information need Management Information System popularly known as MIS. Management Information System is a computer based system. It is a very strong tools available to managers for planning, organizing, executing, monitoring, control and evaluation of their operations efficiently. MIS Facilitates effective communication.

MIS consists of three basic components: Management, Information and the System. Integrated use of these three components enables clarity in understanding the issues involved, impact of each component on other seemingly independent inputs but interconnected with each other. The decisions taken in this way is appropriate in the context of the business requirements. MIS enables to adopt multi-disciplinary management approach considering all the aspects relating to operational, financial, materials, behavioral, organizational practices and policies; and computer related issues. Organization works in holistic manner with the help of MIS rather than in different segments. Decisions in different segments without taking a holistic approach have greater chances of failure. There is tremendous avoidable waste in utilization of organizational resources.

\subsection{MIS supports organizational systems}

Organizational structure basically can be divided in three layers of hierarchy: top management level, middle management level and lower management level (Fig. 2). Each level takes decisions according to their roles.

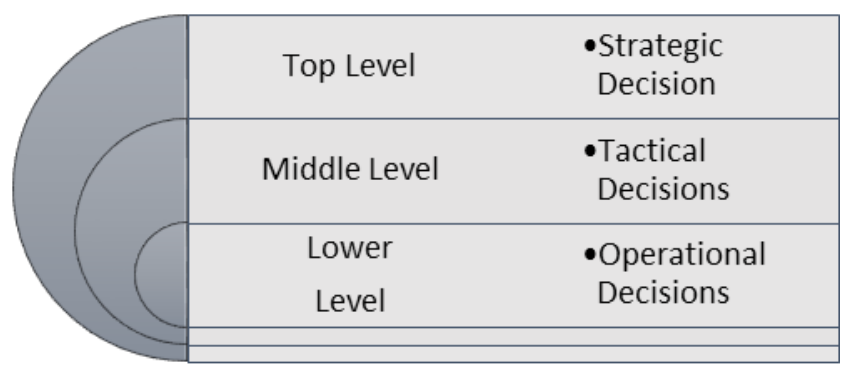

Fig. 2: Decision areas and management levels

The lower level managers are involved in operational decisions, middle level managers' focus on the tactical decisions and top level managers concentrate on strategic decisions. Most of the routine activities are planned, executed and managed by lower level managers for example planning, scheduling and ensuring that all the plans are implemented as decided. Middle level managers spend relatively less time on the routine planning activities and focus more on tactical decisions such as problem solving, gap analysis, performance appraisal and advertising. The role of top managers is very different than the lower level and middle level managers. They mostly concentrate on the strategic issues like which product should be launched in the market, which market should be tapped, how to make entry into the domain of the competitors, how to arrange for various resources, how to improve productivity of the organization, how to reduce cost, with whom to collaborate, whether to computerize, to what extent computerization should be implemented, how to train the manpower to match with 
technological challenges likely to be faced etc. Table 1 shows the level of management hierarchy in an organization, related decision making roles and the type of informations required by them.

\begin{tabular}{|c|c|c|c|}
\hline $\begin{array}{l}\text { Types of } \\
\text { information }\end{array}$ & $\begin{array}{l}\text { Levels of } \\
\text { managers }\end{array}$ & $\begin{array}{l}\text { Types of Decision } \\
\text { Making }\end{array}$ & Examples of information from educational sector \\
\hline $\begin{array}{l}\text { Descriptive } \\
\text { Information }\end{array}$ & $\begin{array}{l}\text { Operational } \\
\text { Level }\end{array}$ & $\begin{array}{l}\text { Policy making and } \\
\text { srategic decisions }\end{array}$ & $\begin{array}{l}\text { Daily schedule of lectures, Teacher absent, } \\
\text {. Alternate arrangement for teacher. }\end{array}$ \\
\hline $\begin{array}{l}\text { Diagnostic } \\
\text { Information }\end{array}$ & $\begin{array}{l}\text { operational / } \\
\text { Middle } \\
\text { Level }\end{array}$ & Tactical decisions & $\begin{array}{l}\text { Why classesdo not start in time? } \\
\text { Why students come late? } \\
\text { Why teachers are late in the class? } \\
\text { Why projector or mic does not work satisfactorily? }\end{array}$ \\
\hline $\begin{array}{l}\text { Predictive } \\
\text { Information }\end{array}$ & $\begin{array}{l}\text { Senior } \\
\text { Middle } \\
\text { Level }\end{array}$ & Tactical decisions & $\begin{array}{l}\text { How to ensure that classes start at right time? } \\
\text { How to improve up-time of projectors and mic systems in the } \\
\text { class rooms. }\end{array}$ \\
\hline $\begin{array}{l}\text { Prescriptive } \\
\text { Information }\end{array}$ & Top Level & Strategic decisions & $\begin{array}{l}\text { How the administrative staff arranges the classes? } \\
\text { Functioning of bio-metric system for attendance }\end{array}$ \\
\hline
\end{tabular}

\section{Information Explosion and Rapid Growth}

In early 1950s, manufacturing units felt a need for better management of operations. Data was needed to schedule the manufacturing activities so that resources of the company are optimally utilized. Wastage due to improper planning in absence of the required data and the information prompted the industry to collect the relevant data required by it for planning, organizing and control of various activities. Computers were also introduced at this time. The need of the business and availability of computers witnessed the beginning of Management Information System (MIS). The purpose of the MIS was to help in better decision making. MIS in the beginning was limited to production records and accounting activities. Development of MIS encouraged the decision makers to make use of the computers in a greater way to improve the speed as well as the quality of decisions taken. Decision making process thus was more demanding for faster and accurate information. This lead to the development of model based decision process, a step ahead of database systems. Development of many useful models like linear programming, transportation model, inventory control model and other optimization models helped the industry and the business to improve its performance.

Accounting systems were found to be quite effective in dealing with the descriptive and diagnostic information but were lacking in managing the predictive and prescriptive information. Improvements in the management skills and need for forward planning led to the development of simulation models. Simulation models were effectively used for training and demonstration purposes for skill improvement. Further developments came in the form of sharing the information. Information could be remotely assessed with the help of a terminal and software. Computer technology brought out number of new advances at this stage. However, it was observed that the data oriented systems did not match the needs of model oriented systems. The problem was addressed through the development of a new system known as Decision Support System (DSS) [3]. It provides the required data quickly to consider many options and make a choice for the most suited option as the decision. The DSS system can consider the various variables to work out the optimum solution. DSS enlarged the information system to many operational areas like production, finance, marketing, and research. DSS enabled efficient maintenance of the data records and helped in saving time and money. Next stage of development in the field of information system was Executive Support System (ESS). Managers can assess the databases of the company and to take relevant data for their analysis and prepare reports or proposals for top managers for decision making. ESS data is highly customized to needs of the company according to its need. Management Support System (MSS) or Process Oriented Information System are similar to ESS.

The combination of database and the model base systems helped the managers to effectively deal with first three types of decisions e.g. operational, tactical and strategic decisions. The decision making was improved substantially but the decision makers were not fully satisfied due to lack of skills and the knowledge at their command. Relevant Expert Systems (ES) were developed to fill up this gap. Development of Expert Systems made the process of decision making very fast. Decisions taken with the help of Expert Systems were better and sound and improved the overall management of the enterprises. The next step in MIS is use of Artificial Intelligence (AI) where in the intelligence is demonstrated by machines or software. Decision making process has achieved a very high speed with the help of intelligence provided by the machines. Fig 3 presents the journey of information systems since 1950s. Various developments in the field of information are shown in 
the figure. This is just a beginning of another phase. As information, technology and communication are interrelated issues, these will be deliberated here.

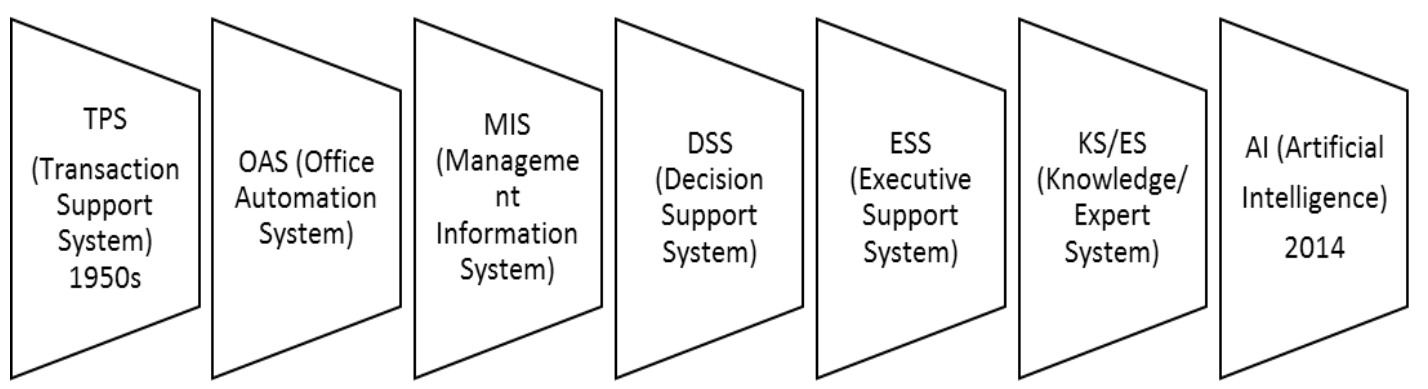

Fig.3: Growth of information systems since 1950s

\section{Trends in MIS}

Technology has contributed to MIS in big way. Introduction of computers, other hardware and software have added to the value of information system. Internet, intranet and extranet have increased the pace of life by quick transfer of data and information across the globe. These aspects are deliberated here.

\subsection{Computer acts as a repository of all the data.}

Processing of data for business decisions and transactions was never fast and easy as is today. This is possible with the introduction of computers and various software which helps in doing the work very fast and accurately. The speed of the work is accelerated to with the programming and dedicated software for particular activities. Facilities of copy, cut, paste, scan, print, edit, translation and checking of plagiarism have added value to the information system and print has changed the transfer of information very fast thus reducing the activity's time. Computers have enabled very fast calculations which otherwise would take many times the time. The quality of work and accuracy produced by the computers has enhanced confidence level in the users in the information system by technological support and done correctly.

\subsection{Power of internet}

The technological developments have changed the way of working of the organizations. Computers has revolutionized the management of the information. Internet has made the information transfer very fast. Today files, pictures, videos can be sent instantly. Sending the information from one place to another place used to take 10-20 days. It can now be delivered instantly without any other person involved in between. Skype, g-talk and many other messenger services has enabled face to face talk very clearly. There is no need to travel physically for discussion or meeting someone. Most of the things can be done on internet. Online sale, purchase, auction, group discussions, webinars, virtual meetings have empowered everyone in the business. Examples of works done easily through internet include payments for electricity bills, telephone bills, booking of tickets for journey by air or rail, making payments online for admission in a university abroad, getting latest information on the available course for admission, applying for admission on line. Education reaches to a very large number of persons through online lessons. Online lessons has enabled everyone to get educated sitting in the house or in the office. Network has connected every one. Google search and other search engines make available large amount of data on the net to help people to find things from anywhere in the world. One is able to send messages faster and correctly. Internet can communicate with other computers or telephones. Companies and individuals can use internet to exchange business transactions, text messages, graphic images, and even video and sound.

\subsection{The Intranet}

Units located at different locations and various departments like marketing, production, materials management, maintenance, finance and human resources are linked to each other through Intranet. Each department can have access to the information required by it online without waiting for the support of other department. The intranet has enabled an integrated management system with the common information system of the organization. This is an internal communication system and sharing of data and information within the organization. Intranet has made the organizations more strong and have become more flexible to easily adjust to changing needs of the customers.

\subsection{Extranet}


Extranet connects one organization with another select organization to share data and information. For example GEC, USA; the manufacturer of turbines share their information on line with their customers and vendors with the help of a password for fast communication and decision making. Similarly a university can share its data and information with the institutes associated with it. Decisions in such situations are not only faster but are taken after considering all the related issues of inter-related institutes or departments.

\subsection{Websites - powerhouse of information sharing}

Websites of the organization give plethora of information which otherwise was unimaginable. Customer can see the details of the products and their specifications, costs, packaging etc. The distance is no issue whether next door or on the other side of the globe. The technological changes has prompted managements of multinationals like IMB, AT\&T and General Motors to their middle managers making the organization flatten. The management process has also undergone changes with the availability of new tools for precise planning, forecasting and monitoring. The web page enables information distribution instantly both within the organization as well as outside the organization. This type of interaction between the companies help them to modify their internal processes and coordinate business processes. Use of electronic media has created digital firms carrying out both internal as well as external functions by electronic systems [4]. A large number of digital firms are linked to each other with the network sharing the business informations about products, product range, pricing, delivery schedule, standards, norms and world class practices.

\subsection{Satellite Images}

Satellite images provide large amount data and information all over the globe. Only few countries in the world have developed the technology expertise in this latest field. The useful information about environment, weather conditions, availability of natural resources, forecasting of coming problems due to tornedos and many other important areas has helped in researching and take timely action to control the damage. Satellite images provide useful information about the land, availability of water, availability of mineral resources necessary to decide on setting up new projects.

\subsection{U-Tube, Face-book and other social sites}

Social media has brought people very close to share their information and be up to date about their friends and relations. Social media is being very effectively used to find information about persons who are potential recruits. Lots of freelancing jobs or head hunting work is being done on the basis of information loaded on the sites. New friendships, new relationships are the results of the information sharing through this media. Technology has become part of today's fast life and has contributed to mankind in making the life easy, happy and enjoyable.

\section{Education: An Important Sector}

Importance of education has been recognized all over the world. All the advanced countries have higher level of education in comparison to the level of education in developing and under-developed countries. The difference in the economy, standard of living, health care, and every other areas can be linked with education. Education empowers to understand issues, think about others, develops an understanding of social responsibility, honesty, no harm to others and not to adopt wrong means. It creates a healthy competition among individuals, groups, departments, organizations and countries. Prosperity and poverty, technological advances, military power, trade and business are linked to the level of education. Education helps in competency building, developing self-confidence and respect to each other. Education contributes in character building and nation building. Countries all over the world have realized the importance of education and have assigned priority to education programs. The constitution of many of the countries lay down education as a fundamental right of the citizens. Federal governments, state governments, local bodies, business houses and non-governmental organizations have focused their attention to this important sector. World organizations like UNESCO, UNDP, World Bank, Asian Development Bank are having number programs to improve the education level of the population [5]. Special emphasis has been given to the education of women and the girls. It has been recognized that to improve the health of the country whether economic health or health of any other area, it is the education of female population which can change the face of the society and the country. Therefore, education is the fore front activity everywhere. It is very important to know the status of education in the country and make plans for further improvements. This calls for an information system.

The issue of 'Education for All (EFA)' was deliberated in the World Education Forum held at Dakar in 2000 [6]. The forum was attended by participants from 150 countries representing 160 governmental and nongovernmental organizations. Progress in the basic education worldwide achieved during the last 10 years since 1990 was reviewed. The focus of the review was to study the status of the achievements made, problems encountered and to decide on the action plans to be pursued. The review showed that majority of countries had an updated database based on regular school census, whose quality and reliability was not sound and not 
suitable for developing suitable policies and strategies. Some of the short comings of the Management Information System (MIS) of various countries included problems of presentation and dissemination of statistical information. Data was found to be in raw form unsupported by proper analysis. An Education Management Information System (EMIS) should be capable to collect, store and process the information. In addition it should also provide the required and accessible information for education policy-making. The role of EMIS has now changed and is seen as an indispensable tool and support system for the formulation of education policies, their management and evaluation. The World Education Forum laid down a target to achieve the goals by the year 2015 [7]. Many of the countries are actively engaged in the EFA programs. Education Management Information System (EMIS) has now become a necessity and a key word. Case studies of Education Management Information System (EMIS) of Nigeria and Zambia are briefly discussed to understand the issues involved and lessons learnt from the experience gained.

\subsection{The Case of EMIS in Nigeria}

The EMIS of Nigeria was specifically designed to collect information of enrolment levels, retention rates, facilities, qualified teachers, faculties and other information from the census form. The purpose of EMIS was to provide support to state level planning and to generate reports. The output of these efforts had a direct impact on the planning process and in identifying the anomalies in the education system [8]. The study showed that EMIS in Nigeria is not effectively used in education planning at the federal as well as state levels. One of the reason for this state of affair is that EMIS lacked the base-line information. The functioning of the government with various layers made it difficult to collect and collate the education data. The planning process in education was not supported by the EMIS due to poor reliability of data and lack of information of the policy directions by the federal government to the various agencies and to the state governments.

Although the role of collecting and collating the data by the federal government, state government and the local bodies was clearly defined in the legislation, yet there were overlapping areas. The EMIS suffered due to difficulties in collection of the survey data, poor commitment from the stakeholders as well as lack of capacity. Another important reason for the failure of EMIS was lack of interest taken by the federal government and poor coordination between state agencies. It was observed that there were resources crunch in collecting the data, analyzing the data collected and transforming the data into policies and strategies. The case of Nigeria showed that although centralization of data collection did not show a weak system but the pilot study taken up with decentralization in collecting the survey data at the state level, revealed that the results were good with decentralization of data collection. It is suggested that this approach may usefully be followed by other developing countries also. Political structure of the government and stability of the government was also seen to have influenced the failure of EMIS. Centralized system, lack of proper structure in the country, lack of knowledge and inadequate training of the staff were identified as the shortcoming of the EMIS of Nigeria.

Development of IT infrastructure helped in technical reforms of EMIS and was definitely a booster in the success of EMIS. Preparation of Education Strategic Plans (ESP) and setting up of a central agency to plan and monitor the program helped in the success of EMIS. Development of standardized software also helped the program. Number of improvements were made on the behest of donor agencies. The latest system developed by Nigeria is named as Nigerian Education Management Information System (NEMIS). It is a web based system under the control of a central agency along with decentralized organization for collection of data. The database of the system has the data of the various states of Nigeria. Initially the data of 28 states was up loaded on EMIS, which was to be further supplemented with the data of 11 more states. The system generated 50 reports. The database covered the education data, publications, training materials at the federal level and similar data of the State Ministry of Education and State Universal Basic Education Board.

The lessons learnt from the case of EMIS of Nigeria are that the role of federal government is very important in the success of EMIS. Developing a good organizational structure both at the central as well as at state level and active participation of private sector in data collection and data analysis contribute greatly in assisting the preparation of plans and strategies for education.

\subsection{Case of EMIS of Zambia}

Zambia has similar situation of education as that of Nigeria. Zambia like many other developing countries has also adopted the goal of 'Education for All (EFA)'. The policy enunciation 'Educating Our Future' is a right policy but its implementation is viewed as ineffective. Zambian government has taken initiative and increased its funding as well as external funding to achieve this objective.

The education system in Zambia is faced some of the challenges specific to country's own scenario. According to the report 'Review of the Ministry of Education Sector Plan Zambia 2006' [9], the Zambian 
students have not been learning enough. The quality of learning has not been good. A large number of Zambians are illiterate. Women especially do not have education and whatever education is acquired is not commensurate to the level. There is shortage of class rooms and many of them are temporary. The class rooms are overcrowded. Teaching and learning resources are not adequate. Teachers are absent. They are under-qualified, untrained and not motivated. Textbooks are not provided to the students. The accountability in the education system is not visible. One of the reason for the poor state of affair is the problem of HIV/AIDs prevailing in the country, which has its impact on the education system also. The Chileshe committee observed that in Zambia there is no keenness to change. The system does not punish poor performance nor does it reward the initiatives.

Number of recommendations have been made by the Expert Committee to take corrective measures. One of the recommendation is to set up an Institute of Education (replacing the Curriculum Development Centre). Also an independent Education Standards Agency is recommended to be established, which would report to the National Education Council and to parliament. The EMIS is to be strengthened to set up an evidence-based policy development unit. The unit's focus should be effective education research. The interaction on policy issues between Ministry of Education (MoE) and the donor community should be filtered through the Lead Donor mechanism. The committee recommended that EMIS department should not only support the MoE with descriptive statistics but should also provide an annual report on "The Policy \& Planning Implications of EMIS" and supplementary sub-sectorial reports. The need is for starting the process of policy making based on evidence. EMIS plays an important role in providing the basic information in this regard. There is a need for an on-going research about what is happening in the class room, at the systems level as well as at macro level.at optimum cost

\subsection{Suggested Approach for an Education Management Information System (EMIS)}

The important question for improving the quality of information and providing the relevant information at the right time and at the right place requires defining the objectives of EMIS. Further considerations are: What should be included in the EMIS? What strategic steps should be taken to ensure that EMIS serves the purpose in providing better education and fulfill the objective of EFA? These issues are discussed here further.

\subsubsection{Objectives of Desirable EMIS}

The objectives of a desirable EMIS are:

a. To provide information on the current status, characteristics, functioning and the results.

b. To make information as one of the main elements of the administration, management and planning of education.

c. To manage, research and plan education by integrating all the sources of information and to provide synthesized reports to the users.

d. To provide a system capable of ensuring the evolution and adaptability of the entire education system.

\subsubsection{Features of Recommended Education Management Information System}

Education Management Information System should have all the features that meets the requirements of all the stake holders related to the field of education. The stake holders include the federal government, state government, local government, universities, institutes, teachers, pupil, parents, civil society and donors. The desirable features of an ideal EMIS are described here:

a. An EMIS should bridge the research and practices with the body of knowledge of information technology [10].

b. EMIS should use Internet, Intranet as well Extranet to have very fast transfer of information and make the decision process very fast. The information should be available when needed for decision making.

c. Latest trends in communication systems e.g. digital communication and digital organization should be incorporated in EMIS.

d. The structure of the EMIS should be such that all level should be able to use the system effectively. The federal government, state government, local government should be linked with each other under the umbrella of central body for education management. Concurrently the decentralized system at the state and local levels should also operate.

e. Software development, software improvements should meet the specific requirements of the system and users.

f. Information produced by EMIS should be users oriented.

g. EMIS should collect, process, analyze and present the data in a manner that helps in effective planning, strategy development and policy formulation.

h. The system should provide various types of information about how much population is ready for education and to take admission in a particular course? How many would be enrolling for admission and how many 
will finally took admission? How many passed out successful? How many class rooms are available? How many teachers are available? What is the shortage of teachers? What is the performance of the teachers? These questions provide information for future plans and to take corrective actions.

i. The system should generate regular reports for consideration of management and other stake-holders.

\section{References}

[1] Harsh, Stephen B., L. J. Connor, and G. D. Schwab, Managing the farm business. Prentice-Hall, Inc., Englewood Cliffs, New Jersey, 1981

[2] Pedarpur, M; etal, 'Management Information systems, functions, structure and its importance - In Manager's Decision Making', IJCRB, Vol. 4, No. 10, 2013, pp 901-997.

[3] House, William C., 'Decision support systems - a data-based, model-oriented user developed discipline, Petrocelli Books, Inc. NY. 1983.

[4] Laudon, K \& Laudon, J., 'Management information systems: managing the digital firms', 9th ed, Prentice Hall, 2006.

[5] Hinchliffe, J.K., Public Expenditure on Education in Nigeria: issues, estimates and some implications, Washington, World Bank, 2002.

[6] Carrizo, L; etal, 'Information tools for the preparation and monitoring of education plans', Education Policies and Strategies, UNESCO, Paris, 2003

[7] Kaduna SMoE, Kaduna State, Education Strategic Plan (ESP) 2006 - 2015, (unpublished), Kaduna SMoE, Final Draft, 2006.

[8] FME EDB, A Handbook of Information on Basic Education in Nigeria, FME EDB, UNESCO, 2002.

[9] Chileshe, John etal, 'Review of the Ministry of Education Sector Plan Zambia 2006, Copenhagen, 2007.

[10] Iivari, Juham, etal, 'Challenges of Professionalization: Bridging Research and Practice through a body of knowledge for IT specialists', IFIP 20th World Computer Congress on Advances in Information Systems Research, Education and Practices, Milano, Italy, 2008, pp 15-28.

\section{ABOUT THE AUTHORS}

1. Hassan Aldarbesti, Qatar Computing Research Institute, Doha, Qatar, Landline; +97444542345

2. J. P. Saxena, PhD, DLL, MBA, DIM, BE (Electrical), BE (Mechanical), Consultant and Visiting Professor, 804, Aspire 1, Supertech Emrald Courts, Sector 93A

Noida, UP, India - 201304, Mobile: +91 999904274, Land Line: 911202426844

Dr. Saxena is Ex-Advisor and Professor on Amity Business School, Amity University Uttar Pradesh, UP (India); Ex-Senior Professor of Jaipuria Institute of Management (India) and Ex-Director R\&D of National Council for Cement \& Building Materials, India. He has authored six books and 50 research papers in International, National Journals, International and National Seminars \& conferences, 